\title{
letters
}

\section{Spinal-anesthesia-induced hypotension study challenged}

To the Editor:

We read with interest the article, "Common features associated with spinal-anesthesiainduced hypotension: A retrospective study" (JAOA 1991; 91:1195-1208). Several aspects of this report merit comment.

It is difficult to study multifactorial events retrospectively. Twenty-five factors have been involved as determinants of local anesthetic spread of solution in cerebrospinal fluid (CSF). ${ }^{1}$ Local anesthetic spread in CSF is only one of many factors associated with hypotension after spinal anesthesia. By the authors' admission, patient position, preoperative medication, anesthetic dosage and concentration, and volume of anesthetic agents were not controlled.

Some factors not addressed may have an even more important role in the development of hypotension following spinal anesthesia. For instance, no mention is made of fluid preloading before initiation of subarachnoid block (SAB), nor was the chosen baricity (hyperbaric, isobaric, or hypobaric) indicated. Given the various factors that influence the development of hypotension following spinal anesthesia, it is necessary to keep the remaining factors constant or at least accounted for, particularly if one factor is to be accurately quantified.

A major criticism of this article is that known hypotensive patients were subjected to spinal blockade, as illustrated in Figure 1. Subsequent post-SAB hypotension was then attributed to preSAB hypotension. Continuing in this vein, Figures 3 and 4 reflect, unfortunately, unknown data. It is unreasonable to include patients in a study in which drug dosages of lidocaine and tetracaine are unknown. We question the rationale behind this inclusion.

The American Society of Anesthesiologists Physical Status (PS) Classification makes no provision for Class 2 to 3 with "mixed features of PS2 and PS3." Ordinal in nature, this classification scheme cannot be expressed as a fraction or as an average as would be appropriate in numerical classification.

Finally, 1985 is the most recent date cited in the 19 references included in this article. It is a reasonable expectation for the most currently available editions of textbooks to be cited.

\footnotetext{
CECIL W. FINCHER, DO MAJ, Medical Corps Staff, Anesthesiology RICHARD B. HECKER, DO CPT, Medical Corps
}

\author{
Staff, Anesthesiology Critical \\ Care \\ Department of the Army \\ Brooke Army Medical Center \\ Fort Sam Houston, Tex
}

1. Greene NM: Distribution of local anesthetic solutions within the subarachnoid space. Anesth Analg 1985;64:715-730.

\section{Response}

\section{To the Editor:}

Because of time constraints, we were compelled to use a retrospective study format for this article. Additionally, the purpose of our study was clearly stated: We intended to identify features common to 85 documented cases of spinalanesthesia-induced hypotension that could predict highrisk cases. Details of baricity, fluid preload, and the like obviously need further evaluation, refinement of technique, and controlled conditions. Perhaps our article will stimulate research along these directions. We made no firm conclusions, just observations.

Regarding the criticism of Figure 1's apparently including known prespinal hypotensive patients, these patients were hemodynamically stable and did have low systolic blood pressure preoperatively. However, they did (continued on page 557) 
Announcing the first of a new NSAID class

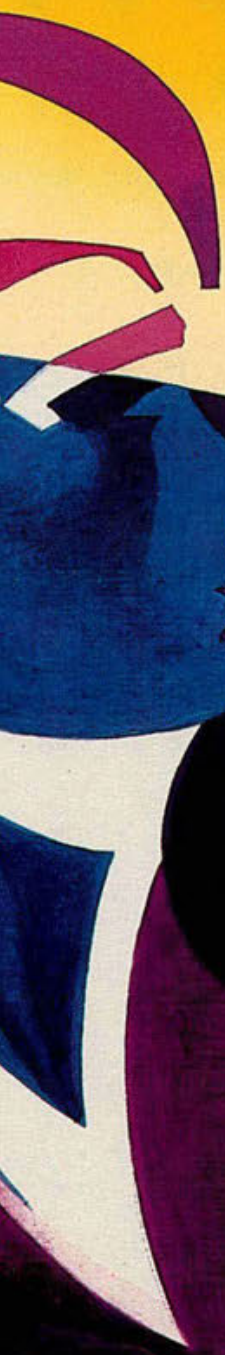

\section{OSTEOARTHRITIS}

AND RHEUMATOID

ARTHRITIS 


\section{Announcing the first of a new NSAID class}
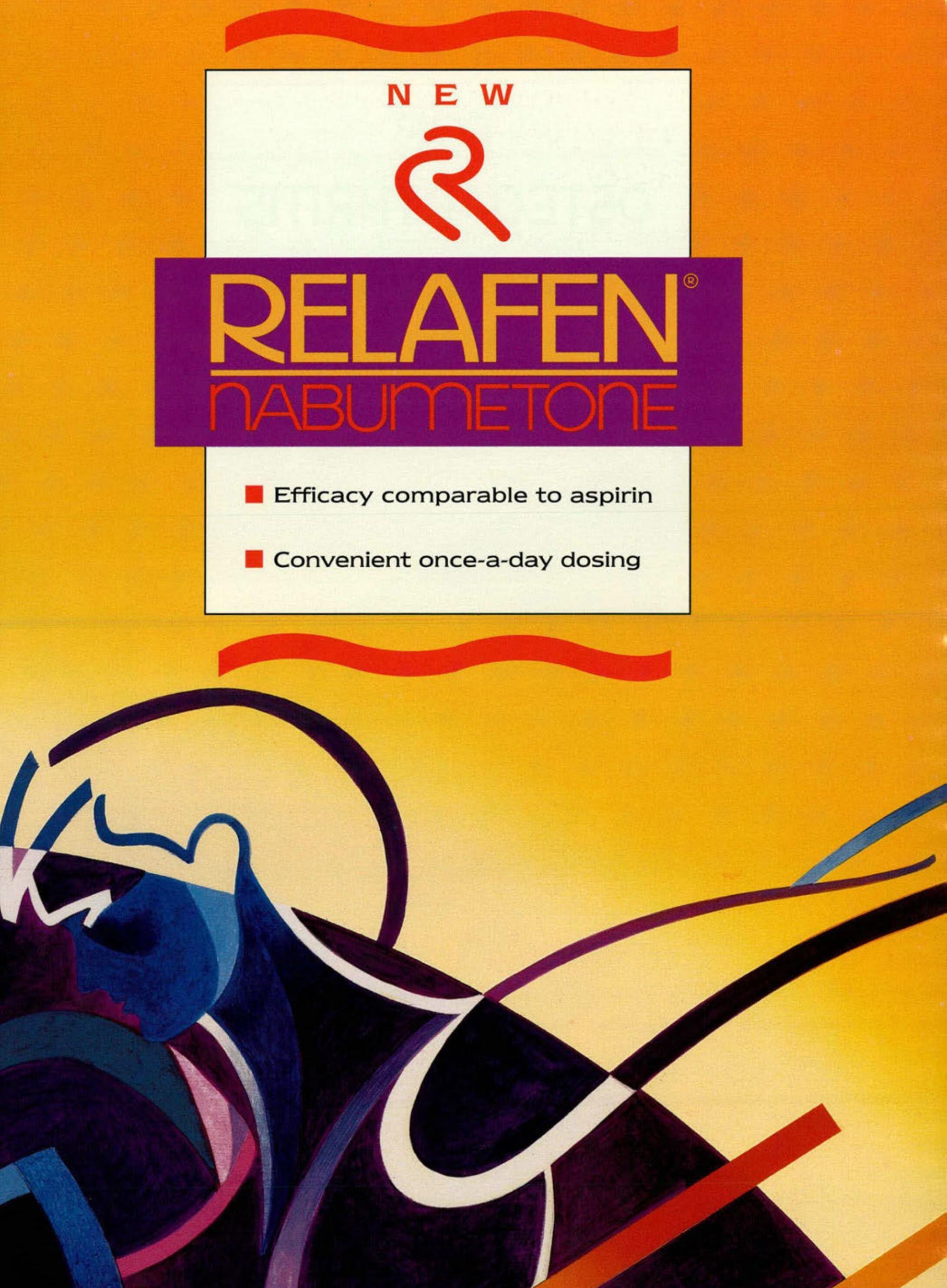


\section{For the treatment of osteoarthritis and rheumatoid arthritis}

Efficacy comparable to aspirin in U.S. clinical trials ${ }^{1}$

\section{Relafen (1000 mg/day) is as effective as aspirin ( $3600 \mathrm{mg} / \mathrm{day}$ )}

In osteoarthritis ${ }^{1}$

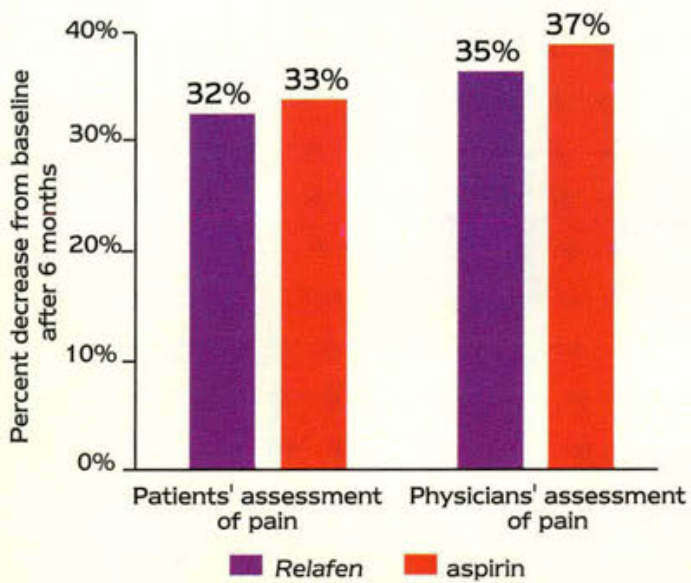

Double-blind comparative trial of 332 patients.
In rheumatoid arthritis ${ }^{2}$

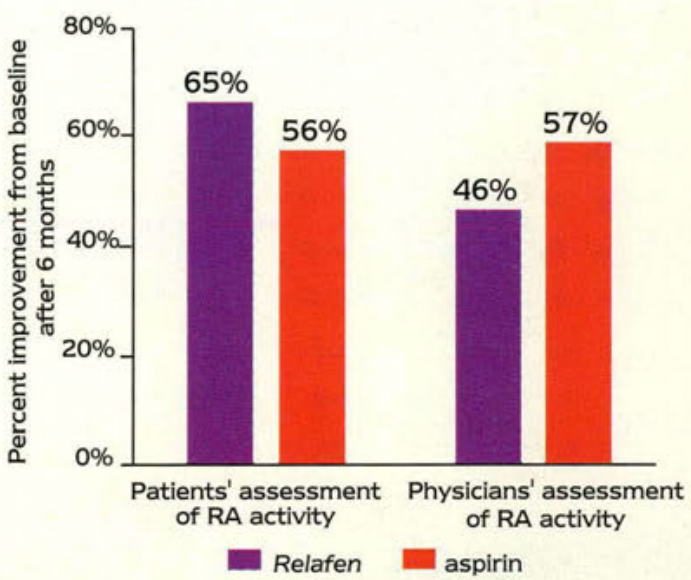

Double-blind comparative trial of 228 patients. 


\section{Arthritis treatment with a low incidence of peptic ulcers}

A low incidence of peptic ulcers in U.S. clinical studies of Relafen 1000 to $2000 \mathrm{mg} / \mathrm{day}$

\begin{tabular}{lcccccc}
\hline Time period & $\begin{array}{c}\text { Cumulative } \\
\text { incidence of } \\
\text { peptic ulcers }\end{array}$ & $\begin{array}{c}95 \% \\
\text { confidence } \\
\text { intervals }\end{array}$ & $\begin{array}{c}\text { Number of patients } \\
1000 \\
\mathrm{mg}\end{array}$ & $\begin{array}{c}1500 \\
\mathrm{mg}\end{array}$ & $\begin{array}{c}2000 \\
\mathrm{mg}\end{array}$ \\
\hline 3 to 6 months & $\mathbf{0 . 3 \%}$ & $(0.0 \%, 0.6 \%)$ & 1064 & 712 & 84 \\
\hline up to 1 year & $\mathbf{0 . 5 \%}$ & $(0.1 \%, 0.9 \%)$ & 833 & 614 & 69 \\
\hline up to 2 years & $\mathbf{0 . 8} \%$ & $(0.3 \%, 1.3 \%)$ & 540 & 513 & 46 \\
\hline
\end{tabular}

- Other G.I. symptoms comparable to other NSAIDs, including diarrhea (14\%), dyspepsia (13\%) and abdominal pain (12\%)

*Patients may have been treated at more than one dosage level. 


\section{Lower incidence of endoscopic lesions ${ }^{\dagger}$ than ibuprofen ${ }^{\ddagger 2}$}

Three-month endoscopic comparison of Relafen ${ }^{\circledR}$, ibuprofen

and ibuprofen plus Cytotec ${ }^{\circledR}$ in 167 patients

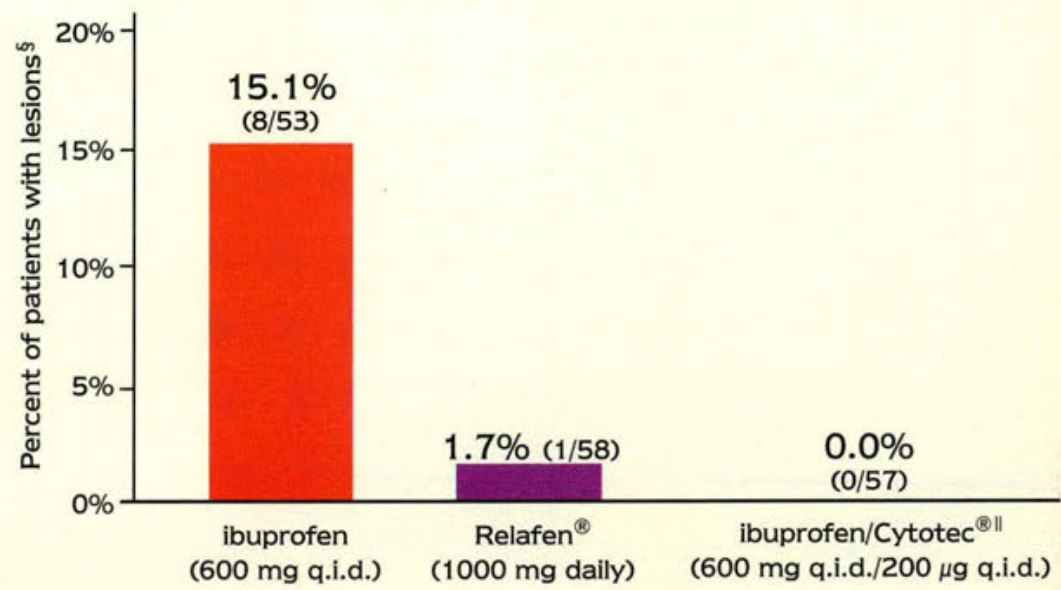

†The trials were not designed to correlate symptoms and endoscopy scores. The clinical relevance of these endoscopy findings, i.e., either G.I. symptoms or serious G.I. events, is not known.

$\ddagger P=0.013$.

$\S$ Lesions defined as $>5 \mathrm{~mm}$.

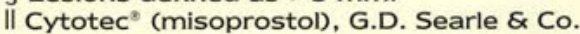
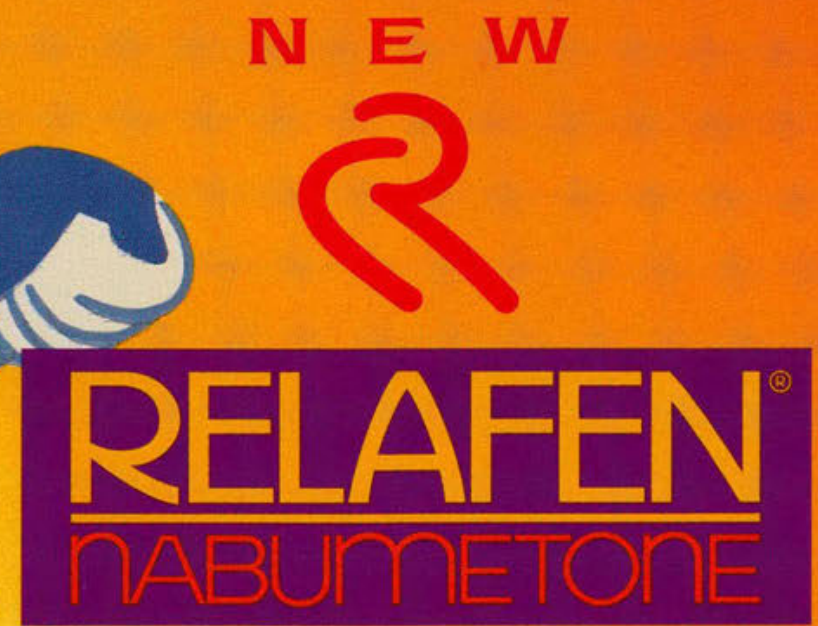

For osteoarthritis and rheumatoid arthritis 


\section{Over 5,000,000 prescriptions dispensed worldwide}

Evaluated in clinical studies with over 40,000 patients ${ }^{2}$

available in over 15 countries

Eight years of worldwide clinical experience

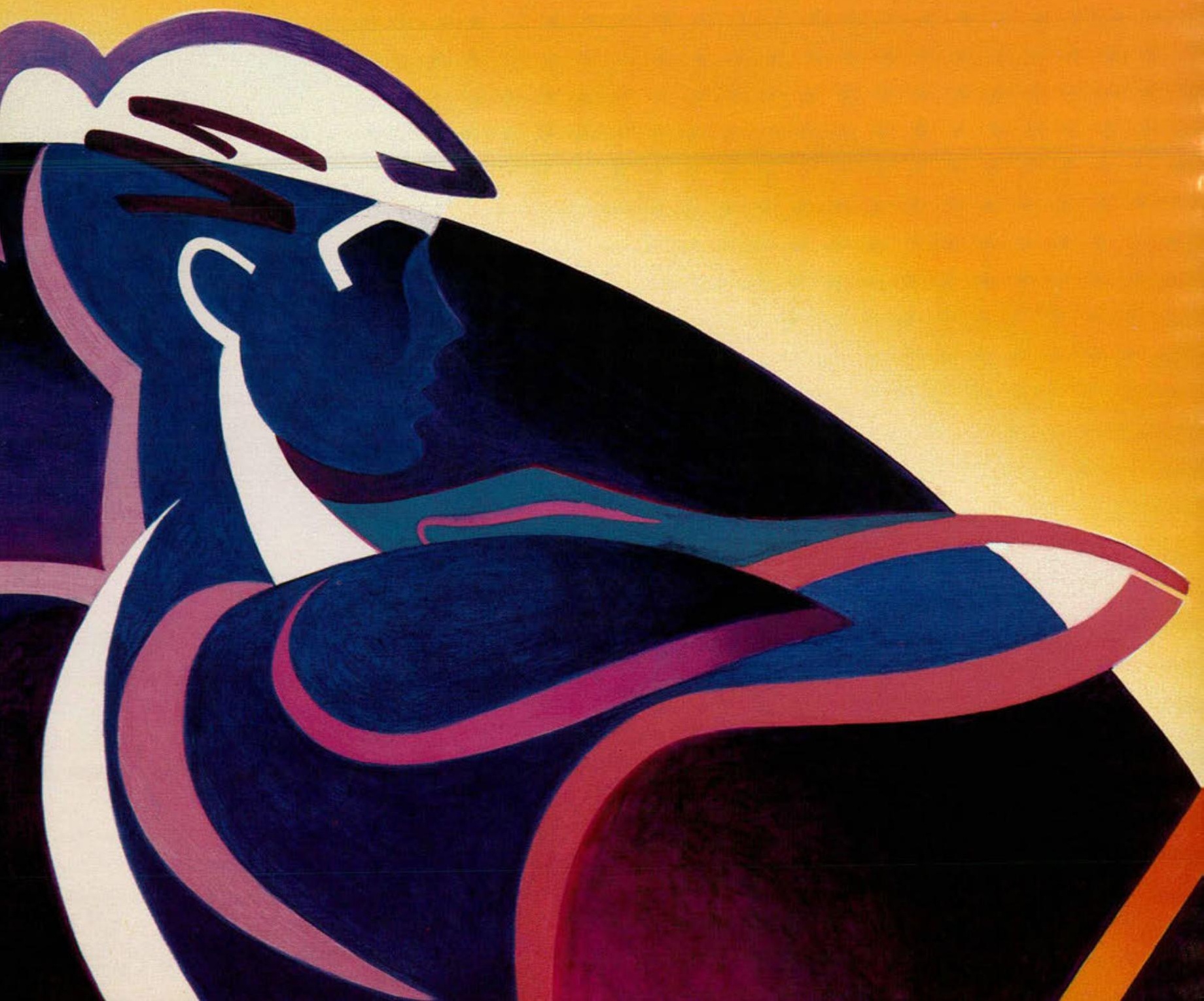




\section{Convenient once-a-day dosing}

Usual starting dose 1000 mg/day, taken as two 500 mg tablets*

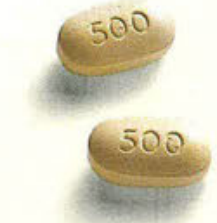

Dosage can be titrated up to $2000 \mathrm{mg} /$ day $^{*}$

- Can be taken with or without food

Food increases the rate but not the extent of absorption

* Please see dosage and administration section of accompanying brief summary of prescribing information.

\section{N E W}

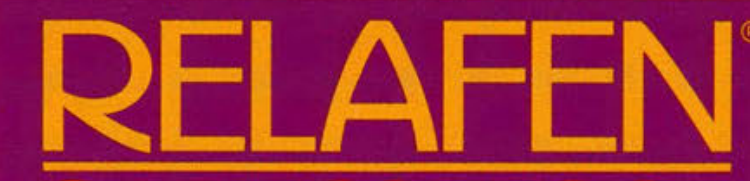

For osteoarthritis and rheumatoid arthritis 


\section{Announcing the first of a new NSAID class}

N E W
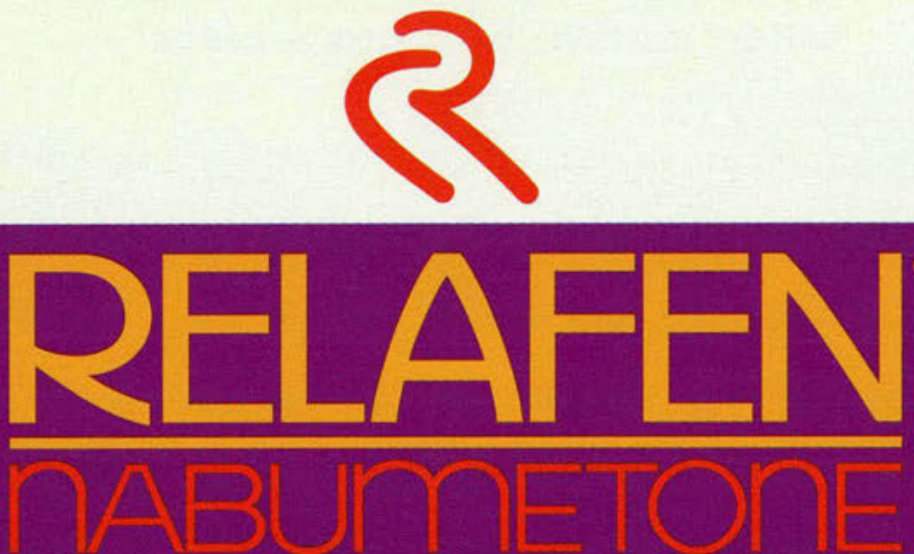

\section{For osteoarthritis and rheumatoid arthritis}

- Efficacy comparable to aspirin

Low incidence of peptic ulcers

- Other G.I. symptoms comparable to other NSAIDs, including diarrhea (14\%), dyspepsia (13\%) and abdominal pain (12\%)

- Convenient once-a-day dosing

- Starting dose $1000 \mathrm{mg} /$ day given as two $500 \mathrm{mg}$ tablets

- Can be titrated up to 2000 mg/day

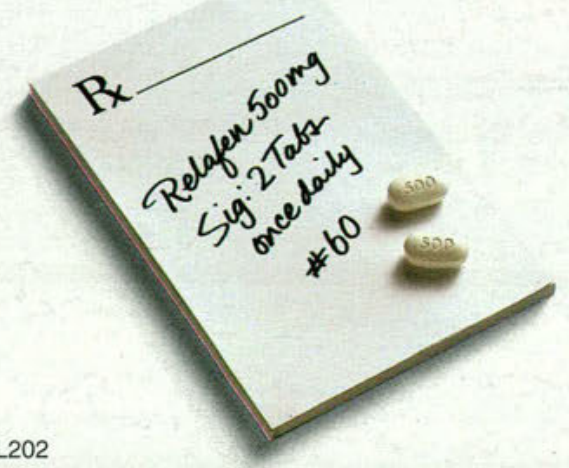

Please see accompanying brief summary of prescribing information.

\section{S3 \\ SmithKlıne Beecham \\ Pharmaceuticals \\ Philadelphia, PA 19101}




\section{RELAFEN}

See complete prescribing information in SmithKline Beecham Pharmaceuticals literature or PDR. The following is a brief summary.

CLINICAL PHARMACOLOGY: Relafen is a nonsteroidal anti-inflammatory drug (NSAID) that exhibits antiinflammatory, analgesic and antipyretic properties in pharmacologic studies. As with other nonsteroidal antiinflammatory agents, its mode of action is not known. However, the ability to inhibit prostaglandin synthesis may be involved in the anti-inflammatory effect.

The parent compound is a prodrug. which undergoes hepatic biotranstormation to the active component, 6-methoxy-2-naphthylacetic acid (6) MNA), a potent inhibitor of prostaglandin synthesis.

INDICATIONS AND USAGE: Acute and chronic treatment of signs and symptoms of osteoarthritis and rheumatoid arthritis.

CONTRAINDICATIONS: Patients (1) who have previously exhibited hypersensitivity to it; (2) in whom Relafen, aspirin or other NSAID sinduce asthma, urticaria or other allergic-type reactions.

WARNINGS: Remain alert for ulceration and bleeding in patients treated chronically, even in the absence of

previous G.I. tract symptoms. two years), the cumulative incidence of peptic ulcers was $0.3 \%$ at three to six months, $0.5 \%$ at one year and $0.8 \%$ at two years. Inform patients of the signs and symptoms of serious G.I. toxicity and what steps to take if they occur. In patients with active peptic ulcer, weigh the benefits of Relafen therapy against possible hazards, institute an appropriate ulcer treatment regimen and monitor the patients' progress carefully.

In considering the use of relatively large doses (within the re

PRECAUTIONS: Because nabumetone undergoes extensive hepatic metabolism, no adjustment of Relafen dos age is generally necessary in patients with renal insufficiency. However, as with all NSAIDs, monitor patients with impaired renal function more closely than patients with normal renal function.

Evaluate patients with symptoms and/or signs suggesting liver dysfunction, or in whom an abnormal liver test has occurred, lor eviderce or the deve If linical a a m and if systemic manitestations occur (e. ensinophilia, rash, etc.), discontinue Relaten. Use Relafen cautiously in patients with severe hepatic impairment.

As with other NSAIDs, use Relafen cautiously in patients with a history of congestive heart failure, hypertension

or other conditions predisposing to fluid retention.
Based on U.V. light photosensitivity testing. Relafen may be associated with more reactions to sun exposure than might be expected based on skin tanning types.

Physicians may wish to discuss with their patients the potential risks (see WARNINGS, PRECAUTIONS and ADVERSE REACTIONS) and likely benefits of NSAID treatment, particularly when the drugs are used for less serious conditions where treatment without NSAIDs may represent an acceptable alternative to both the patient and the physician.

Exercise caution when administering Relafen with warfarin since interactions have been seen with other NSAIDs. In two-year studies conducted in mice and rats, nabumetone had no statistically significant tumorigenic effect Nabumetone did not show mutagenic potential in the Ames test and mouse micronucieus test in vivo. However, higher concentrations (equal to the average human exposure to Relaten at the maximum recommended dose). Nabumetone did not impa i f fertility of mage or female rats treated orally at doses of $320 \mathrm{mg} / \mathrm{kg} / \mathrm{day}$ before mating. Pregnancy Category C: Nabumetone did not cause any teratogenic effect in rats given up to $400 \mathrm{mg} / \mathrm{kg}$ and in rabbits up to $300 \mathrm{mg} / \mathrm{kg}$ orally. However, increased post-implantation loss was observed in rats at $100 \mathrm{mg} / \mathrm{kg}$ orally and at higher doses (equal to the average human exposure to 6MNA at the maximum recommended human dose). There are no adequate, well-controlled studies in pregnant women. Use the drug during pregnancy only if clearly needed. Because of the known effect of prostaglandin-synthesis-inhibiting drugs on the human fetal cardiovascular system (closure of ductus arteriosus), use of Relafen during the third trimester of pregnancy is not recommended.

列

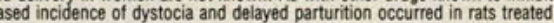

It is not known whether nabumetone or its metabolites are excreted in human milk; however, 6MNA is excreted in the milk of lactating rats. Because of the possible adverse effects of prostaglandin-synthesis-inhibiting drugs on neonates. Relafen is not recommended for use in nursing mothers.

Safety and efficacy in children have not been established.
of the 1,677 patients in U.S. clinical studies who were treated with Relafen, 411 patients $(24 \%)$ were 65 years of age or older; 22 patients (1\%) were 75 years of age or older. No overall differences in efficacy or safety were observed between these older patients and younger ones. Similar results were observed in a one-year, non-U.S. postmarketing surveillance study of 10,800 Relafen patients, of whom 4,577 patients ( $42 \%$ ) were 65 years of

ADVERSE REACTIONS: Incidence $\geq 1 \%$ - Probably Causally Related-Diarrhea (14\%), dyspepsia (13\%), abdominal pain $(12 \%)$, constipation ", flatulence", nausea ", positive stool guaiac", dry mouth, gastritis, stomatitis, vomiting, dizziness ${ }^{*}$, headache ${ }^{*}$, fatigue, increased sweating, insomnia, nervousness, somnolence,

pruritus ", rash", tinnitus" edema ${ }^{*}$.

Incidence $<1 \%$ - Probably Causally Related: - Anorexia, cholestatic jaundice, duodenal ulcer, dysphagia gastric ulcer, gastroenteritis, gastrointestinal bleeding, increased appetite, liver function abnormalities, meight asin, bullous eruptions, photosensitivity, urticaria pseudoporphyria cutanea tarda, dyspnea, abnorma vision, albuminuria, interstitial nephritis, angioneurotic edema

Incidence $<1 \%$ - Causal Relationship Unknownt - Duodenitis, eructation, gallstones, gingivitis, glossitis, pancreatitis, rectal bleeding, acne, alopecia, erythema multiforme, Stevens-Johnson Syndrome, asthma, cough, azotemia, bilirubinuria, dysuria, hematuria, impotence, renal stones, taste disorder, fever, chills, angina, arrhythmia, hypertension, myocardial infarction, palpitations, syncope, thrombophlebitis, anemia, leukopenia, granulocytopenia, thrombocytopenia, hyperglycemia, hypokalemia, weight loss, nightmares.
$\dagger$ Adverse reactions reported only in worldwide postmarketing experience or in the literature are italicized.

OVERDOSAGE: If acute overdose occurs, empty the stomach by vomiting or lavage and institute general supportive measures as necessary. Activated charcoal, up to 60 grams, may eftectively reduce nabumetone absorption. Coadministration of nabumetone with charcoal to man has resulted in an $80 \%$ decrease in maximum plasma concentrations of the active metabolite.

One overdose occurred in a 17-year-old female patient who had a history of abdominal pain and was hospitalized for increased abdominal pain following ingestion of 30 Relafen tablets ( 15 grams total). Stools were negative for occult blood and there was no fall in serum hemoglobin concentration. The patient had no other symptoms. Sh Was given an

DOSAGE AND ADMINISTRATION: Recommended starting dose: $1000 \mathrm{mg}$ taken as a single dose with or without food. Some patients may obtain more symptomatic relief from $1500 \mathrm{mg}$ to $2000 \mathrm{mg}$ dally. Dosages over 2000 $\mathrm{mg}$ daily have not been studied. Use the lowest effective dose for chronic treatment.

HOW SUPPLIED: Tablets: Oval-shaped, film-coated: $500 \mathrm{mg}$ - white, imprinted with the product name RELAFEN and 500, in bottles of 100 and 500 , and in Single Unit Packages of 100 (intended for institution use only); $750 \mathrm{mg}$-beige, imprinted with the product name RELAFEN and 750, in bottles of 100 and 500 , and in Single Unit tackages of 100 (intended for institutional use only

Store at controlled room temperature $\left(59^{\circ}\right.$ to $\left.86^{\circ} \mathrm{F}\right)$ in well-closed container; dispense in light-resistant container $500 \mathrm{mg}$ 100's: NDC 0029-4851-20 $500 \mathrm{mg}$ SUP 100 's: NDC 0029-4851-21

$750 \mathrm{mg}$ 100's: NDC 0029-4852-20

o SmithKline Beecham, 1992

BRS-RL:L2

References:

1. Appelrouth DJ, Baim S, Chang $C W$, et al: Comparison of the safety and efficacy of nabumetone and aspirin in the treatment of osteoarthritis in adults. Am J Med 1987:83 (suppl 48):78-81.

2. Data on file, Medical Department, SmithKline Beecham Pharmaceuticals.

\section{MOVING?}

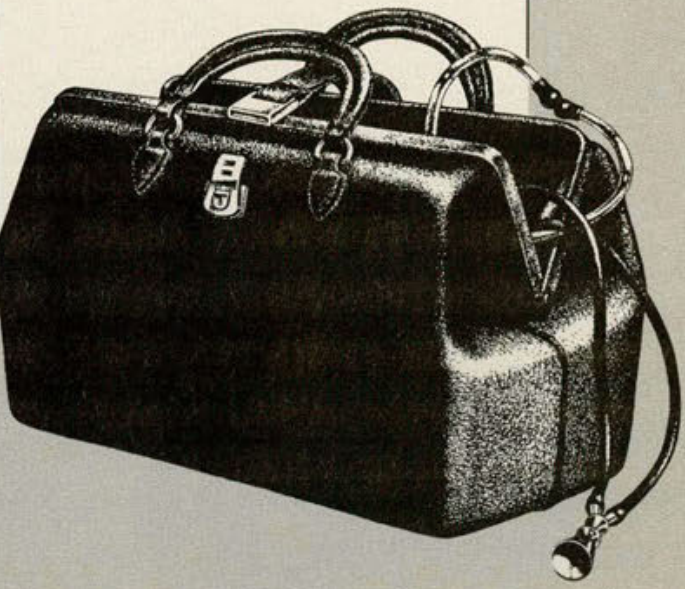

\section{Don't forget The JA0A}

Attach your current mailing label, print your new address in the space provided, and mail this form to:

Circulation Department

American Osteopathic

Association

142 E. Ontario St.

Chicago, IL 60611

New Address:

Name

AOA Number

Address

City/State/Zip
AFFIX LABEL HERE

Please allow 4-6 weeks for delivery. 
In hypertension
Only one ACE inhibitor guarantees your patients a lifetime of savings!

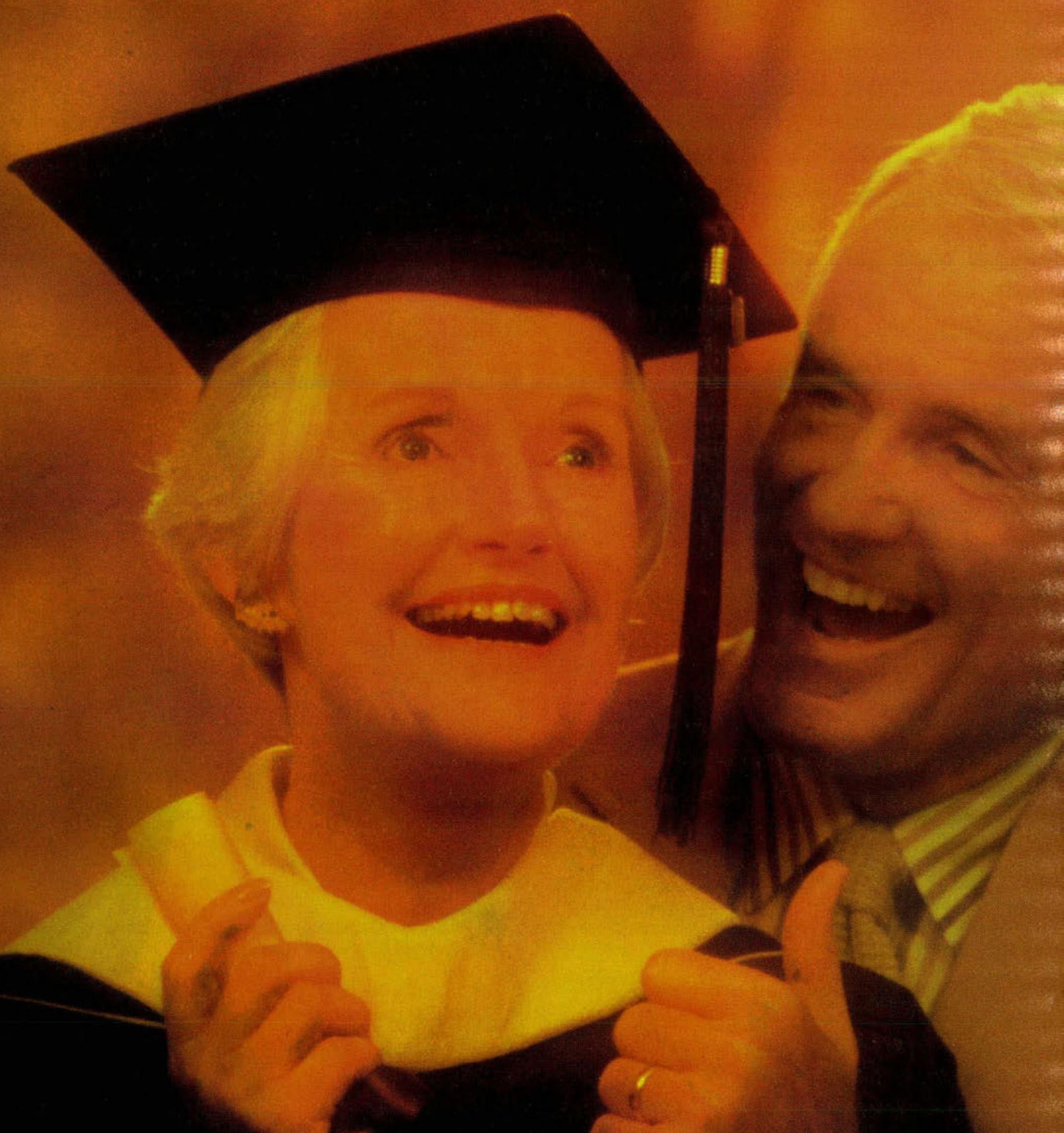



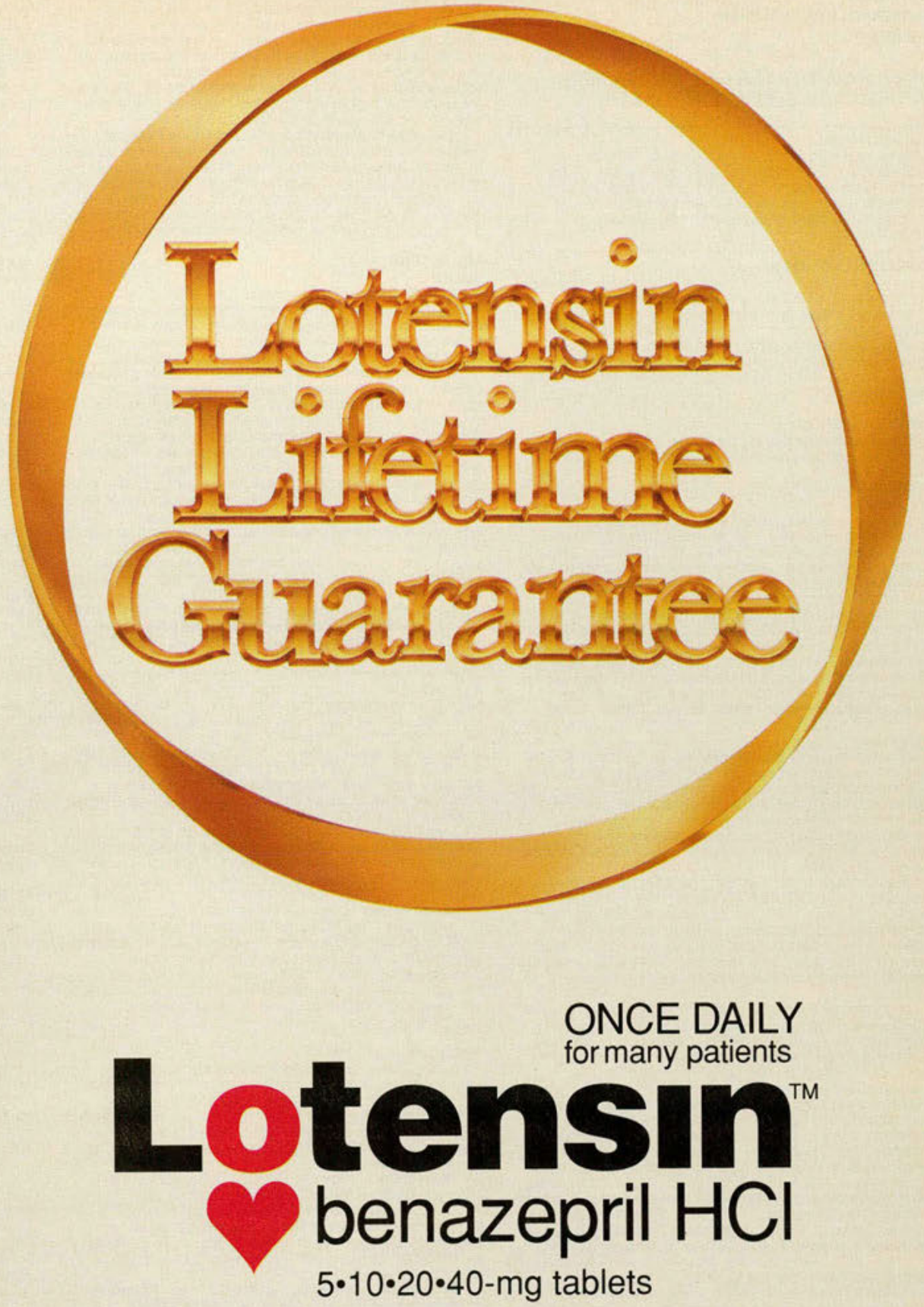

The price your patients start with is the price they stay with*

\section{For information, call: 1-800-621-0021}

Angioedema has been reported in patients receiving ACE inhibitors. Because ACE inhibitors can cause injury and even death to the developing fetus, when pregnancy is detected ACE inhibitors should be discontinued as soon as possible. Please consult brief summary of Prescribing Information on last pages.

\section{I B A}




\section{Lotensin ${ }^{\circledR}$ benazepril hydrochloride Tablets}

\section{BRIEF SUMMARY. FOR FULL PRESCRIBING INFORMATION, SEE PACKAGE INSERT}

\section{Use in Pregnancy \\ When used in pregnancy during the second and third drimesth to the developitors can cause injury and eve death to the developing fetus. When pregnancy is possible. See WARNINGS, Fetal/Neonatal Morbidity}

\section{NDICATIONS AND USAGE}

Lotensin is indicated for the treatment of hypertension. It may be used alone or in combination with thiazide diuretics.

In using Lotensin, consideration should be given to the fact that another angiotensin-converting enzyme inhibitor, captopril, has another angiotensin-converting enzyme inhibitor, captopril, impairment or collagen-vascular disease, Available data are
insufficient to show that Lotensin does not have a similar risk (see WARNINGS).

\section{CONTRAINDICATIONS}

A patients who are

hypersensitive to this product or to any other ACE inhibitor.

\section{WARNINGS}

Angioedema larynx has been reported in patients treated with angiotensinconverting enzyme inhibitors. In U.S. clinical trials, symptoms consistent with angioedema were seen in none of the subjects who received placebo and in about $0.5 \%$ of the subjects who received Lotensin. Angioedema associated with laryngeal edema can be fatal. If laryngeal stridor or angioedema of the face, tongue, or glottis occurs, treatment with Lotensin should be discontinued and appropriate therapy instituted immediately. Where there is involvement of the tongue, glottis, or larynx, likely to cause
airway obstruction, appropriate therapy, e.g., subcutaneous airway obstruction, appropriate therapy, e.g., subcutaneous
epinephrine injection $1: 1000(0.3 \mathrm{~mL}$ to $0.5 \mathrm{~mL})$ should be promptly administered (see ADVERSE REACTIONS).

\section{Hypotension}

Lotensin can cause symptomatic hypotension. Like other ACE inhibitors, benazepril has been only rarely associated with hypotension in uncomplicated hypertensive patients. Symptomatic hypotension is most likely to occur in patients who have been rolume andor sall-depleted as a result of prolonged diuretic therapy, dietary salt restriction, dialysis, diarrhea, or vomiting.
Volume-and/or salt-depletion should be corrected before initiatin therapy with Lotensin.

In patients with congestive heart failure, with or without associated renal insufficiency, ACE inhibitor therapy may cause excessive hypotension, which may be associated with oliguria or azotemia and, rarely, with acute renal faliure and death. In such patients, Lotensin therapy should be started under close medical treatment and whenever the dose of benazepril or diuretic is increased.

If hypotension occurs, the patient should be placed in a supine position, and, if necessary, treated with intravenous infusion of physiological saline. Lotensin treatment usually can be continued
following restoration of blood pressure and volume.

\section{Neutropenia/Agranulocytosis}

Another angiotensin-converting enzyme inhibitor, captopril, has been shown to cause agranulocytosis and bone marrow depression, rarely in uncomplicated patients, but more frequently in patients with renal impairment, especially if they also have a collagen-vascular disease such as systemic lupus erythematosus
or scleroderma. Available data from clinical trials of benazepril are or scificient to show that benazepril does not cause agranulocytosis insufficient to show that benazepril does not cause agranulocytosis
at similar rates. Monitoring of white blood cell counts should be at similar rates. Monitoring of white blood cell counts should be considered in patients with collagen-vascular disease,
the disease is associated with impaired renal function.

\section{Fetal/Neonatal Morbidity and Mortality}

ACE inhibitors can cause fetal and neonatal morbidity and death when administered to pregnant women. Several dozen cases have
been reported in the world literature. When pregnancy is detected, ACE inhibitors should be discontinued as soon as possible. The use of ACE inhibitors during the second and third trimesters of pregnancy has been associated with fetal and neonatal injury, including hypotension, neonatal skull hypoplasia, anuria, reversible or irreversible renal failure, and death Oligohydramnios has also been reported, presumably resulting has been associated with fetal limb contractures, craniofacial deformation, and hypoplastic lung development. Prematurity, intrauterine growth retardation, and patent ductus arteriosus have also been reported, although it is not clear whether these occurrences were due to the ACE inhibitor exposure. These adverse effects do not appear to have resulted from intrauterine ACE inhibitor exposure that has been limited to the firs trimester. Mothers whose embryos and fetuses are exposed to ACE inhibitors only during the first trimester should be so informed. Nonetheless, when patients become pregnant, physicians should make every effort to discontinue the use of benazepril as soon as possible.

Rarely (probably less often than once in every thousand pregnancies), no alternative to ACE inhibitors will be found. In these rare cases, the mothers should be apprised of the potential hazards to their fetuses, and serial ultrasound examinations should be performed to assess the intraamniotic environment. If oligohydramnios is observed, benazepril should be discontinued unless it is considered life-saving for the mother. Contraction stress testing (CST), a nonstress test (NST), or biophysical profiling (BPP) may be appropriate, depending upon the week of pregnancy. Patients and physicians should be aware, however, that oligohydramnios may not appear until after the fetus should be closely observed for hypotension, oliguria, and hyperkalemia. If oliguria occurs, attention should be directed toward support of blood pressure and renal perfusion. Exchange transfusion or dialysis may be required as means of reversing hypotension and/or substituting for disordered renal function. Benazepril, which crosses the placenta, can theoretically be removed from the neonatal circulation by these means; there are occasional reports of benefit from these

No teratogenic effects of Lotensin were seen in studies of pregnant rats, mice, and rabbits. On a $\mathrm{mg} / \mathrm{m}^{2}$ basis, the doses used in these studies were 60 times (in rats), 9 times (in mice), and more than 0.8 times (in rabbits) the maximum recommended human dose (assuming a $50 \mathrm{~kg}$ woman). On a mg/kg basis these
multiples are 300 times (in rats), 90 times (in mice) and more than 3 times (in rabbits) the maximum recommended human dose.

\section{PRECAUTIONS \\ General}

Impaired Renal Function: As a consequence of inhibiting the renin-angiotensin-aldosterone system, changes in renal function may be anticipated in susceptible individuals. In patients with severe congestive heart failure whose renal function may depend on the activity of the renin-angiotensin-aldosterone system, treatment with angiotensin-converting enzyme inhibitors, including Lotensin, may be associated with oliguria and/or progressive azotemia and (rarely) with acute renal failure and/or death. In a small study of hypertensive patients with renal artery stenosis solitary kidney or bilateral renal artery stenosis, treatment with serum creatinine; these increases were reversible upon discontinuation of Lotensin or diuretic therapy, or both. When such patients are treated with ACE inhibitors, renal function should be monitored during the first few weeks of therapy. Some

hypertensive patients with no apparent preexisting renal vascular disease have developed increases in blood urea nitrogen and serum creatinine, usually minor and transient, especially when Lotensin has been given concomitantly with a diuretic. This is more likely to occur in patients with preexisting renal impairment. Dosage reduction of Lotensin and/or discontinuation of the diuretic may be required. Evaluation of the hypertensive patient should ADMINISTRATION)

Hyperkalemia: In clinical trials, hyperkalemia (serum potassium at least $0.5 \mathrm{mEq} / \mathrm{L}$ greater than the upper limit of receiving Lotensin. In most cases, these were isolated values which resolved despite continued therapy. Risk factors for the development of hyperkalemia include renal insufficiency, diabetes mellitus, and the concomitant use of potassium-sparing diuretics, potassium supplements, and/or potassium-containing salt substitutes, which should be used cautiously, if at all, with Lotensin (see Drug interactions).

Cough: Cough has been reported with the use of ACE inhibitors. Characteristically, the cough is nonproductive, persistent, and resolves after discontinuation of therapy. ACE inhibitor-induced cough should be considered as part of the differential diagnosis of cough.

Impaired Liver Function: In patients with hepatic dysfunction e to cirrhosis, levels of benazeprilat are essentially unaltered. Surgery/Anesthesia: In patients undergoing surgery or during anesthesia with agents that produce hypotension, benazepri w block the angiotensin II formation that could otherwise occur as a result of this mechanism can be corrected by volume expansion.

\section{Information for Patients}

Pregnancy: Female patients of childbearing age should be told about the consequences of second-and third-trimester exposure to ACE inhibitors, and they should also be told that these

consequences do not appear to have resulted from intrauterine ACE inhibitor exposure that has been limited to the first trimester. These as soon as possible.

Angioedema: Angioedema, including laryngeal edema, can occur with treatment with ACE inhibitors, especially following the first dose. Patients should be so advised and told to report immediately any signs or symptoms suggesting angioedema (swelling of face, eyes, lips, or tongue, or difficulty in breathin and to take no more

Symptomatic Hypotension: Patients should be cautioned that
Sym Symptomatic Hypotension: Patients should be cautioned the
lighteades can occur, especially during the first days of therapy, and it should be reported to the prescribing physician. Patients should be told that if syncope occurs, Lotensin should be discontinued until the prescribing physician has been consulted. All patients should be cautioned that inadequate fluid intake or excessive perspiration, diarrhea, or vomiting can lead to an excessive fall in blood pressure, with the same consequences of .

Hyperkalemia: Patients should be told not to use potassium supplements or salt substitutes contani

Neutropenia: Patients should be told to prom ptly report any indication of infection (e.g., sore throat, fever), which could be sign of neutropenia.

\section{Drug Interactions}

Diuretics: Patients on diuretics, especially those in whom diuretic therapy was recently instituted, may occasionally experience an with Lotensin. The possibility of hypotensive effects with Lotensin with Lotensin. The possibility of hypotensive effects with Lotensin the salt intake prior to initiation of treatment with Lotensin. If this is not possible, the starting dose should be reduced (see DOSAGE not possible, the starting

Potassium Supplements and Potassium-Sparing Diuretics: Lotensin can attenuate potassium loss caused by thiazide diuretics. Potassium-sparing diuretics (spironolactone, amiloride, triamterene, and others) or potassium supplements can increas the risk of hyperkalemia. Therefore, if concomitant use of such
agents is indicated, they should be given with caution, and the agents is indicated, they should be given with caution, and
patient's serum potassium should be monitored frequently. Oral Anticoagulants: Interaction studies with wartarin and acenocoumarol failed to identify any clinically important effects on

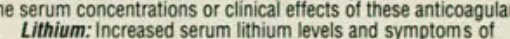

lithium toxicity have been reported in patients receiving ACE inhibitors during therapy with lithium. These drugs should be coadministered with caution, and frequent monitoring of serum
lithium levels is recommended. If a diuretic is also used, the risk ithium toxicity may be increased

Other: No clinically important pharmacokinetic interactions occurred when Lotensin was administered concomitantly with hydrochlorothiazide, chlorthalidone, furosemide, digoxin,

propranolol, atenolol, naproxen, or cimetidine.

Lotensin has been used concomitantly with beta-adrenergicblocking agents, calcium-channel-blocking agents, diuretics digoxin, and hydralazine, without evidence of clinically important
adverse interactions. Benazepril, like other ACE inhibitors, has had less than additive effects with beta-adrenergic blockers. presumably because both drugs lower blood pressure by inhibitin parts of the renin-angiotensin system.

\section{Carcinogenesis, Mutagenesis, Impairment of Fertility}

No evidence of carcinogenicity was found when benazepril was administered to rats and mice for up to two years at doses of up to $150 \mathrm{mg} / \mathrm{kg} /$ day. When compared on the basis of body weights, this compared on the basis of body surface areas, this dose is 18 and times (rats and mice, respectively) the maximum recommended human dose (calculations assume a patient weight of $60 \mathrm{~kg}$ ). No mutagenic activity was detected in the Ames test in bacteria (with mutation metabolic activation), in an in vitro test for forward test. In doses of $50-500 \mathrm{mg} / \mathrm{kg} /$ day $(6-60$ times the maximum recommended human dose based on $\mathrm{mg} / \mathrm{m}^{2}$ comparison and 37 375 times the maximum recommended human dose based on a $\mathrm{mg} / \mathrm{kg}$ comparison), Lotensin had no adverse effect on the 作

Pregnancy Categories C (first trimester) and D

second and third trimesters

See WARNINGS, Fetal/Neonatal Morbidity and Mortality.

\section{Nursing Mothers}

Minima amounts of unchanged benazepril and of benazeprilat are excreted into the breast milk of lactating women treated with benazepril. A newborn child ingesting entirely breast milk would and benazeprilat.

Geriatric Use

Of the total number of patients who received benazepril in U.S. clinical studies of Lotensin, $18 \%$ were 65 or older while $2 \%$ were 75 or older. No overall differences in effectiveness or safety were observed between these patients and younger patients, and other reported clinical experience has not identified differences in responses between the elderly and younger patients, but greater sensitivity of some older individuals cannot be ruled out.

Pafety and effectiveness in children have not been established.

Lotensin has been evaluated for safety in over 6000 patients with hypertension; over 700 of these patients were treated for at least one year. The overall incidence of reported adverse events was mparable in Lotensin and placebo patients.

The reported side effects were generally mild and transient, an there was no relation between side effects and age, duration of therapy, or total dosage within the range of 2 to $80 \mathrm{mg}$.

Discontinuation of therapy because of a side effect was required in of patients treated with . patients

The most common reasons for discontinuation were headache $(0.6 \%)$ and cough $(0.5 \%)$. (See PRECAUTIONS, Cough).

The side effects considered possibly or probably related to study drug that occurred in U.S. placebo-controlled trials in mor
than $1 \%$ of patients treated with Lotensin are shown below.

PATIENTS IN U.S. PLACEBO-CONTROLLED STUDIES

\begin{tabular}{|c|c|c|c|c|}
\hline & ${ }_{(\mathrm{N}}^{\mathrm{L}}$ & & & \\
\hline Headache & $\frac{10}{60}$ & $\frac{\%}{6.2}$ & $\frac{N}{21}$ & $\frac{\%}{4.2}$ \\
\hline Dizziness & 35 & 3.6 & 12 & 2.4 \\
\hline Fatigue & 23 & 2.4 & 11 & 2.2 \\
\hline Somnolence & 15 & 1.6 & 2 & 0.4 \\
\hline Postural Dizziness & 14 & 1.5 & 1 & 0.2 \\
\hline Nausea & 13 & 1.3 & 5 & 1.0 \\
\hline Cough & 12 & 1.2 & 5 & \\
\hline
\end{tabular}

Cough $\quad 12 \quad 1.2 \quad 5 \quad 1.0$ (in less than $1 \%$ of benazepril patients), and rarer events seen in postmarketing experience, include the following (in some, a causa Pre is uncertain):

Cardiovascular: Symptomatic hypotension was seen in $0.3 \%$ patients, postural hypotension in $0.4 \%$, and syncope in $0.1 \%$; thes received benazepril monotherapy and in 9 patients who had received benazepril with hydrochlorothiazide (see PRECAUTIONS and WARNINGS). Other reports included angina pectoris, palpitations, and peripheral edema.

Renal: Of hypertensive patients with no apparent preexisting renal disease, about $2 \%$ have sustained increases in serum creatinine to at least $150 \%$ of their baseline values while receiving Lotensin, but most of these increases have disappeared despite continuing treatment. A much smaller fraction of these patients (less than $0.1 \%$ ) developed simultaneous (usually transient) 


\section{OVERDOSAGE}

Single oral doses of $3 \mathrm{~g} / \mathrm{kg}$ benazepril were associated with significant lethality in mice. Rats however, tolerated single oral doses of up to $6 \mathrm{~g} / \mathrm{kg}$. Reduced activity was seen at $1 \mathrm{~g} / \mathrm{kg}$ in mice and at $5 \mathrm{~g} / \mathrm{kg}$ in rats. Human overdoses of benazepril have not been reported, but the most common manifestation of human benazepril overdosage is likely to be hypotension.

Laboratory determinations of serum levels of benazepril and its metabolites are not widely available, and such determinations have, in any event, no established role in the management of benazepril overdose.

No data are available to suggest physiological maneuvers (e.g., maneuvers to change the $\mathrm{pH}$ of the urine) that might accelerate elimination of benazepril and its metabolites. Benazeprilat can be removed from the body by dialysis, but this intervention should rarely, if ever, be required.

Angiotensin II could presumably serve as a specific antagonistantidote in the setting of benazepril overdose, but angiotensin II is essentially unavailable outside of scattered research facilities. Because the hypotensive effect of benazepril is achieved through vasodilation and effective hypovolemia, it is reasonable to treat benazepril overdose by infusion of normal saline solution.

Storage: Do not store above $86^{\circ} \mathrm{F}\left(30^{\circ} \mathrm{C}\right)$. Protect from moisture. Dispense in tight container (USP).

\section{I B A}

\section{Dist. by:}

CIBA Pharmaceutical Company

Division of CIBA-GEIGY Corporation

Summit, New Jersey 07901

- CIBA Pharmaceutical Company has established the Lotensin Lifetime Guarantee for patients who are started on Lotensin and enrolled in the program. As part of the Lotensin Lifetime Guarantee, the Lotensin Lifetime Guarantee Price (based on Average Wholesale Price) has been established. This price is guaranteed for as long as the patient is on Lotensin therapy. Patients who enroll will be rebated the difference between the Lifetime Guarantee Price and any higher price that can be documented as paid with an original receipt. Because retail prices may vary, a maximum rebate has been established. This rebate will be increased, as needed, to account for any price increases.

have a further decrease in blood pressure following subarachnoid block. In such cases, the drop in systolic blood pressure of more than 30 torr applied. Including these patients was appropriate; this decrease would have been recorded in each patient's anesthesia records. Many of these patients were healthy pregnant women.

Because multiple factors were evaluated, those three patients without lidocaine or tetracaine doses listed were included in Figures 3 and 4 to show the reader that not all parameters were listed on each patient's data sheet. As you noted, this flaw is inherent in retrospective studies; your criticism is valid.

We used the definition of Physical Status (PS) Class 2 to 3 to explain data from 8 patients' charts that were classified as PS 2 to 3 . This deficiency supports your contention that a retrospective format probably is not the best method for this research. Despite this, we did not want to exclude these patients' data from our study. Perhaps these data should have been assigned to Class 3 to eliminate this misunderstanding; your expert opinions are valid.

Although we were unable to access the most recent references, the material we did use was appropriate for the purpose of our article. Interestingly, the reference you cite in your letter is dated 1985.

Despite our article's shortcomings, we believe that it could be helpful in predicting spinal-anesthesia-induced hypotension. It is our hope that our article, along with your critique, will stimulate further research in this area.

STEPHEN M. SWETECH, DO Macomb Hospital Corp and First Care Medical Center Detroit, Mich

JUSTIN W. CONLON, DO

Chairman, Department of Anesthesia

Michigan Health Center Hospital

Detroit, Mich

ANTHONY S. MESSANA, DO

Chairman, Department of Surgery

Michigan Health Center Hospital

Detroit, Mich 


\section{OSTEOPATHIC}

RESEARCH:

AGENDA FOR

THE FUTURE

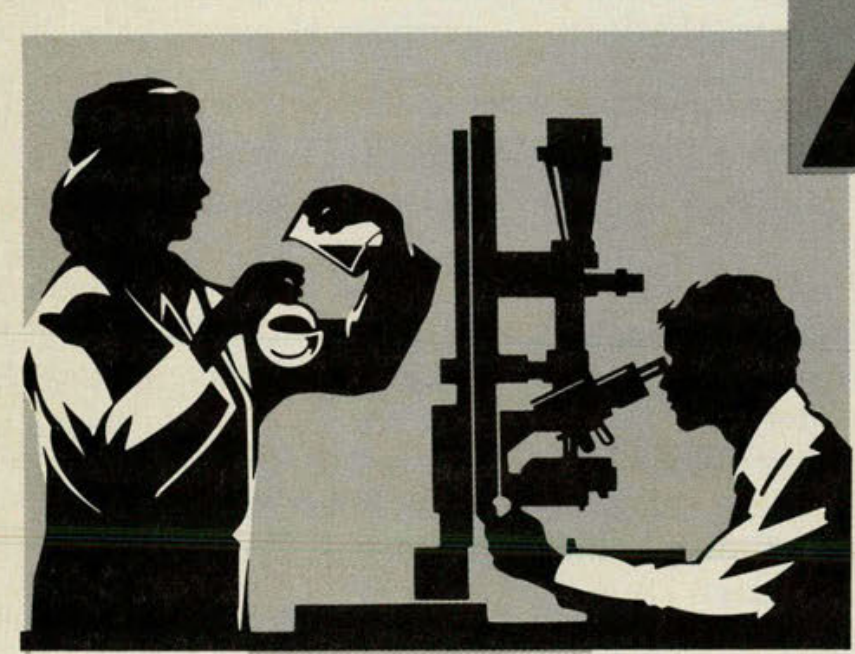

UNDER THE SPONSORSHIP OF

THE BUREAU OF RESEARCH OF THE

\section{$A \Omega$}

American Osteopathic Association 36th Annual Research Conference NOVEMBER 1-4, 1992
SAN DIEGO, CA NOVEMBER 1-4,
SAN DIEGO, CA
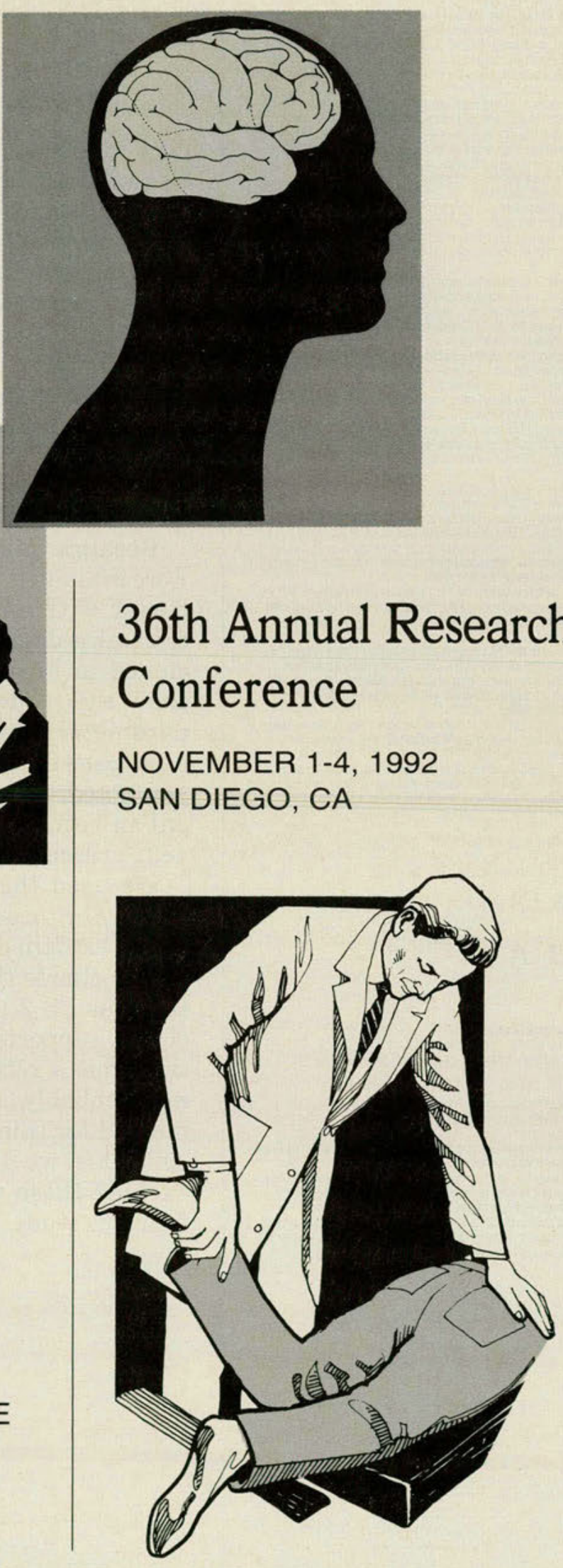
Osteopathic Association's Bureau of Research, we would like to take this opportunity to invite you to attend the 36th

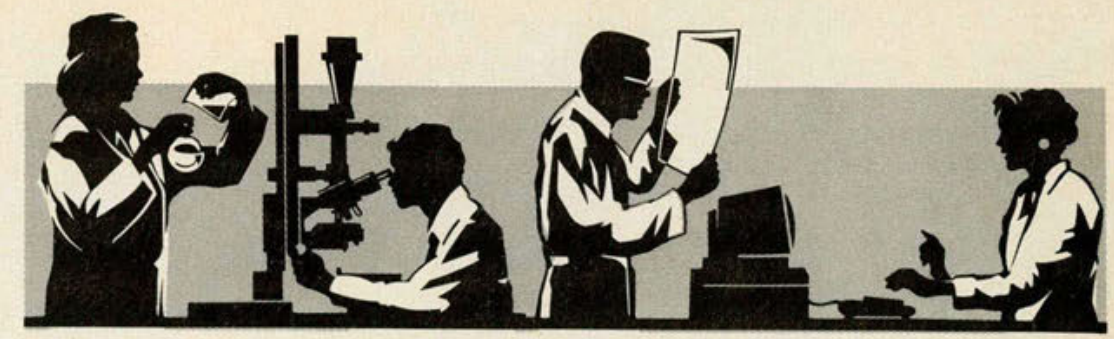

Annual Research Conference. The theme of this year's conference is "Osteopathic Research:

Agenda for the Future". The three day scientific program will include general contributions presented in both slide and poster format. Also, this year's Research Conference opening session will feature a special lecture by the winner of JAOA George Northup Writing Award, Irvin Korr, Ph.D. for his paper Osteopathic Research: The Needed Paradigm Shift. "The Interrelationship of the Neuroendocrine-immune systems" will be the topic of the Forum on Wednesday and will include a discussion of osteopathically oriented research done in this area.

The conference will again be meeting with the 97th Annual AOA Convention and Scientific Seminar. This arrangement has and will offer biomed ical and clinical researchers several professional opportunities to learn more about research interests in the clinical disciplines and will assist in developing collaborative research programs with

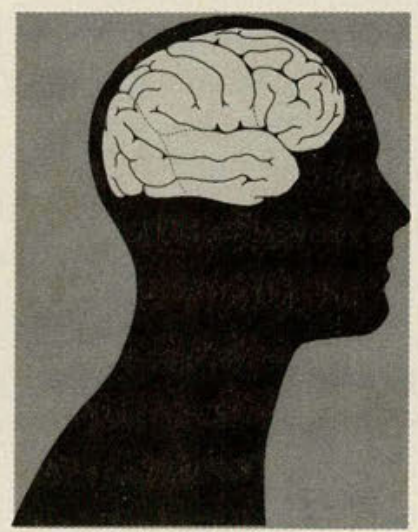
If you are interested please contact the Research Director at your college. For further information contact:

\section{AOA Department of Education}

Division of Research \& Predoctoral Education

Konrad C. Retz, Ph.D. $\square$ (800) 621-1773 or (312) 280-5864

Andrea L. Change $\square$ (312) 280-5874

We hope that you include the 1992 Research Conference as part of your convention activities and look forward to seeing you in San Diego.

\section{Lex Towns, $\mathrm{Ph} \mathrm{D}$}

Program Chairman, 1992 Research Conference

\section{Anthony J. Silvagni, DO, Pharm D}

Chairman, Committee on Research

Conferences

Howard M. Levine, DO

Chairman, Bureau of Research

clinical investigators and meeting with the members of the AOA Bureau of Research and its committees.

At this time we are requesting abstracts for both the slide and poster sessions. Abstract packets will be sent to the research offices of all colleges of osteopathic medicine on April 1. 